\title{
Sodium sources in the Japanese diet: difference between generations and sexes
}

\author{
Keiko Asakura ${ }^{1,2}$, Ken Uechi $^{2}$, Shizuko Masayasu ${ }^{3}$ and Satoshi Sasaki ${ }^{2, *}$ \\ ${ }^{1}$ Interfaculty Initiative in Information Studies, The University of Tokyo, Tokyo, Japan: ${ }^{2}$ Department of Social and \\ Preventive Epidemiology, School of Public Health, The University of Tokyo, 7-3-1 Hongo, Bunkyo-ku, Tokyo, Japan: \\ ${ }^{3}$ lkurien-naka, Ibaraki, Japan
}

Submitted 12 March 2015: Final revision received 2 October 2015: Accepted 19 0ctober 2015: First published online 17 November 2015

\begin{abstract}
Objective: Globally, the Na consumption of most people exceeds the WHO recommendation. To be effective, salt reduction programmes require assessment of the dietary sources of $\mathrm{Na}$. Due to methodological difficulties however, comprehensive assessments are rare. Here, we identified $\mathrm{Na}$ sources in the Japanese diet using a $4 \mathrm{~d}$ diet record that was specifically designed for Na source description.

Design: A cross-sectional study.

Subjects: Apparently healthy men ( $n$ 196) and women ( $n$ 196) aged 20-69 years. Setting: The subjects were recruited from twenty-three of forty-seven prefectures in Japan.

Results: The proportion of discretionary $\mathrm{Na}$ intake in total $\mathrm{Na}$ intake was $52.3 \%$ in men and $57.1 \%$ in women, and was significantly lower in younger subjects. The two major food groups contributing to $\mathrm{Na}$ intake were seasonings such as salt or soya sauce $(61.7 \%$ of total $\mathrm{Na}$ intake in men, $62.9 \%$ in women) and fish and shellfish $(6.7 \%$ in men, $6.6 \%$ in women). The third major contributor differed between men and women (noodles in men, $4.9 \%$; bread in women, $5.0 \%$ ). Further, the contribution of each food group to total Na intake differed among age groups.

Conclusions: While individual efforts to decrease $\mathrm{Na}$ intake remain important, population approaches to reducing $\mathrm{Na}$ content in processed foods are already equally important and will assume greater importance in the future even in Japan, an Asian country facing a rapid Westernization in dietary habits.
\end{abstract}

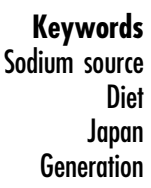

Decreasing salt intake reduces the incidence of noncommunicable diseases, such as coronary artery disease and stroke, and remains an important global priority in the public health field ${ }^{(1-4)}$. Recently, He et al. reported a successful nationwide salt reduction programme in the UK that reduced population salt intake by $15 \%$ from 2003 to $2011^{(5,6)}$. As significant decreases in mortality from stroke and IHD and in blood pressure were observed in the same period, the authors claimed that these positive results were attributable to the reduction ${ }^{(6)}$. Similarly, a Finnish team reported a successful national salt reduction effort that promoted healthy nutrition and produced a decrease in blood pressure ${ }^{(7)}$. Despite these programmes, however, mean salt intake has remained above the WHO recommendation $(<5 \mathrm{~g} / \mathrm{d})$ in both populations ${ }^{(7-9)}$. In addition to population-based interventions, several counselling methods or interventions for individuals have also been proposed $^{(10)}$, but their implementation in primary-care settings was shown to be unfeasible ${ }^{(10)}$. Further efforts to reduce salt intake are therefore required.
Before a salt reduction programme is planned and initiated, current $\mathrm{Na}$ consumption and sources of $\mathrm{Na}$ in the diet must be assessed ${ }^{(5)}$. We recently estimated mean $\mathrm{Na}$ consumption in the Japanese population and clarified that most Japanese consumed a much higher level of Na than the WHO recommendation ${ }^{(11)}$. Although salt reduction is particularly urgent for Japanese, no comprehensive evaluation of $\mathrm{Na}$ sources in the Japanese diet has yet appeared. Shimbo et al. showed that approximately $50-60 \%$ of the $\mathrm{NaCl}$ intake by Japanese was derived from salt-containing seasonings, such as miso (fermented soyabean paste), soya sauce and table salt ${ }^{(12)}$. While Miura et al. reported that persons with higher salt intake consumed higher amounts of soyabeans/legumes, fruit, other vegetables and fish/shellfish ${ }^{(13)}$, they did not report the contribution of the individual food groups to $\mathrm{Na}$ intake. Anderson et al. reported dietary sources of $\mathrm{Na}$ for Japanese as a result of the INTERMAP study ${ }^{(14)}$. However, the sum of percentage $\mathrm{Na}$ from foods and food groups in their study was $84.4 \%$; namely, foods contributing $15.6 \%$ 
of $\mathrm{Na}$ intake in Japanese were not shown. Also, since food groups adopted in their study did not follow the classifications used in the Standard Tables of Food Composition in Japan ${ }^{(15)}$, it is difficult to utilize the result for salt reduction in daily life. In addition, data collection for these three studies was done from the 1980s to the 1990s, and recent Na sources in Japanese are unknown. Further, the person or entity with immediate responsibility for the $\mathrm{Na}$ content of a meal is unclear; if most $\mathrm{Na}$ comes from processed foods, the efforts of food manufacturers are important, but if discretionary salt intake (salt added during cooking at home or at the table) is dominant in the Japanese diet, interventions aimed at personal dietary habits are also important.

Since sources of $\mathrm{Na}$ in the diet vary by country, effective interventions to reduce salt intake must be customized for each country. In general, the main source of dietary Na for people in Europe and North America is processed foods such as bread, processed meat and cheese ${ }^{(14,16-18)}$. For example, salt intake from bread is $34.6 \%$ in the $\mathrm{UK}^{(14)}$, $19.5 \%$ in the $\mathrm{USA}^{(14)}$ and $13.9 \%$ in Canada ${ }^{(18)}$. In contrast, discretionary $\mathrm{Na}$ intake accounts for more than half of total intake in several countries in Asia, Africa and South America ${ }^{(19-22)}$; in particular, more than $70 \%$ of $\mathrm{Na}$ in China $^{(14)}$ Brazil $^{(22)}$ and Guatemala ${ }^{(20)}$ is discretionary.

Here, we examined $\mathrm{Na}$ sources in the Japanese diet using recent diet record data collected from twenty-three of forty-seven prefectures in Japan. Each recorded food was classified in accordance with who was responsible for the $\mathrm{Na}$ content in that food, namely the individuals themselves or food manufacturers. This classification was then used to determine targets for effective interventions to reduce salt intake. In addition, the contribution of each food group to total $\mathrm{Na}$ intake was investigated.

\section{Methods}

\section{Study participants}

Details of the study design and participant characteristics have been reported elsewhere ${ }^{(11)}$. Briefly, the study targeted apparently healthy men and women aged 20-69 years living in twenty study areas (twenty-three prefectures in total: three study areas included two adjacent prefectures) throughout Japan. First, 199 dietitians working in separate welfare facilities were recruited to support the study as research dietitians. These dietitians then invited their facility co-workers to participate as study subjects. The participants were not randomly sampled, but were volunteers. Exclusion criteria were: (i) licensed dietary or medical provider (e.g. dietitian, nurse or medical doctor); (ii) residence in the prefecture or prefecture adjacent to that in which the facility was located (workplace at the time of the study) commencing after 1 August 2012; (iii) under diet therapy prescribed by a doctor or dietitian at the time of the study or within one year before the study; (iv) pregnant or lactating women; and (v) history of educational admission for diabetes mellitus.

In total, 791 subjects (395 men and 396 women) participated in the study. The research dietitians explained the aims and procedure of the study to all participants individually. Written informed consent was obtained from all participants.

\section{Measurement schedule}

All measurements were made in February or March 2013. Main examination items were semi-weighed diet records (DR; obtained from 392 participants), $24 \mathrm{~h}$ urine collection (two non-consecutive days), three questionnaires (two types of diet history questionnaire and one lifestyle questionnaire) and anthropometric measurements (body height and weight). First, four non-consecutive survey days for the DR were arranged. Then, two $24 \mathrm{~h}$ urine collections were planned before and after the four DR days. The questionnaire surveys were performed between the first urine collection and the first DR. The measurement schedule aimed to complete all measurements within 10 to $14 \mathrm{~d}$ and was arranged by the research dietitian and the participant him- or herself in consideration of the participant's work and private schedules.

\section{Semi-weighed diet record}

Half of the study participants $(n$ 400) were asked to complete a DR over four non-consecutive days, and 392 complied (participation rate: 98\%). These participants were selected on a volunteer basis. This reduction in subject number for the DR was necessary to reduce the workload of the research dietitians in checking recording sheets and to improve data quality. On average, twenty subjects participated in the DR survey from each study area. Adjustment of age and sex in each research area made at recruitment was retained even in these participants; in other words, each area generally included four subjects (two men and two women) from each of five 10-year age bands.

The four recording days for the DR consisted of three working days and one day off. The days before and after a night shift were avoided as recording days. All participants were provided a digital kitchen scale (KD-812WH; Tanita, Tokyo, Japan), measuring spoon, measuring cup, manual for the DR and recording sheets. The research dietitian directly explained the recording methods to the participants and supported them throughout the survey.

The participants recorded all foods and drinks consumed by them on the survey days. They weighed ingredients in dishes, prepared dishes after cooking and all drinks using the provided digital scale whenever possible. If participants ate out and weighing was difficult, they recorded the restaurant's name, name of dishes and whether any food was left uneaten. Since it was essential for the present study to comprehend the types and 
amounts of consumed seasonings such as salt or soya sauce, the participants were asked to list the names and manufacturers of all seasonings that they usually used at home on the recording sheet. The main items recorded on the DR sheets were: (i) names of dishes; (ii) names of foods and any ingredients in dishes; (iii) whether the foods were home-made or ready-made; (iv) approximate amount of foods consumed (amount measured by measuring spoon or measuring cup, or number of consumed foods (e.g. two strawberries)); (v) measured weight of each ingredient, food and/or dish; and (vi) place where the participant had the meal. In addition, the participants were asked to submit packages of processed foods or snacks with the recording sheet for estimation of ingredients.

The recording sheets for each survey day were handed directly to the research dietitian immediately after recording and then checked by the research dietitian as soon as possible. If missing or unclear information was recorded by a participant, the research dietitian questioned the participant directly. After this confirmation process, food item numbers ${ }^{(15)}$ were assigned to all recorded foods and beverages, and if necessary, consumed weight was estimated as precisely as possible utilizing the information recorded for the approximate amount of food, the website of the restaurant or manufacturer, or the nutrition facts on the food package. Recorded food items and weights were then reconfirmed by two research dietitians at the central office of the study. Nutritional value calculations were performed with the statistical software package SAS version 9.3.

\section{Twenty-four-hour urine collection}

Twenty-four-hour urine collection was performed on two non-consecutive days during the study period. Details of the collection method have been reported elsewhere ${ }^{(11)}$. One $\mathrm{mmol}$ of $\mathrm{Na}$ is equal to approximately $58.5 \mathrm{mg}$ of salt $(\mathrm{NaCl})$.

\section{Other measurements}

Body height and weight were measured to the nearest $0.1 \mathrm{~cm}$ and $0.1 \mathrm{~kg}$, respectively, with the participant wearing light clothing and no shoes. Measurement was done by the research dietitian or medical staff (mainly nurses) at the welfare facility. BMI was calculated as body weight (in kilograms) divided by the square of body height (in metres). Information on the background and lifestyle of the participants was collected by questionnaire. Physical activity level was estimated by summing the product of the time spent on each of a range of activities with various exercise intensities and the metabolic equivalent (MET) value for each activity ${ }^{(23)}$.

\section{Data analysis}

All 392 participants who completed the DR were included in the analysis. Energy intake estimated by the DR of all participants except one was between $\geq 0.5$ times the estimated energy requirement (EER) for people with the lowest physical activity level (EER I, shown in the Dietary Reference Intakes for Japanese, 2010 ${ }^{(24)}$ ) and $<1.5$ times the EER for those with the highest physical activity level $\left(\right.$ EER III $\left.{ }^{(24)}\right)$. This range was used as an inclusion criterion in several previous studies ${ }^{(25,26)}$. The one male participant whose energy intake was $48.8 \%$ of EER I was included in the analysis as an exception. The research dietitian who checked his DR noted that the amounts of foods consumed were low immediately after the survey and confirmed recorded values with the participant several times, but no obvious misrecording was identified. Regarding $24 \mathrm{~h}$ urine collection, 376 of the 392 participants who completed the DR also collected urine successfully ${ }^{(11)}$ and were included in the analysis of urinary $\mathrm{Na}$ excretion.

To distinguish discretionary $\mathrm{Na}$ intake from nondiscretionary intake, all recorded foods or ingredients in each dish were initially classified into three categories: home-made, processed or other (Fig. 1). The 'home-made' category includes foods cooked at home and having a specific item number in the Standard Tables of Food Composition in Japan ${ }^{(15)}$, such as cooked well-milled rice or yoghurt made at home. The 'processed' category included foods that were processed by the manufacturer and had a specific item number, such as processed meat (e.g. ham, sausages), fish paste products or dairy products (e.g. cheese, ice cream). All foods prepared and consumed at all types of restaurant were classified as 'processed', because $\mathrm{Na}$ intake at a restaurant cannot be controlled by the participant. The 'other' category included any unprocessed ingredients before cooking at home, such as vegetables, meats, fish or milk. Seasonings added during home cooking and used at the table at home were included in the 'other' category. In this classification, $\mathrm{Na}$ intake from the foods categorized as 'home-made' or 'other' was considered discretionary intake. On the other hand, intake from foods in the 'processed' category was considered non-discretionary $\mathrm{Na}$ intake.

All foods and ingredients were then reclassified into three intake source groups using the categories described above and the place where the participant had the meal. The three groups were: (i) the 'self-cooking' group, including foods and ingredients categorized as 'home-made' or 'other' and consumed at home or outside (e.g. box lunch); (ii) the 'ready-made' group, including those in the 'processed' category and consumed at home; and (iii) the 'dining out' group, including those in the 'processed' category and consumed outside the home. For this classification, $\mathrm{Na}$ intake from foods in the 'selfcooking' group was considered discretionary, and intake in the 'ready-made' and 'dining out' groups was considered non-discretionary. This grouping was used in the subsequent analysis.

Crude and energy-adjusted (by the density method $^{(27)}$ ) $\mathrm{Na}$ intake estimated by the DR was summarized by sex, 
Step 1: Foods were categorized into one of three categories shown below.

1. Home-made: foods cooked at home with specific food item numbers (e.g. cooked well-milled rice, home-made yoghurt $) \leftarrow$ Salt was added by the participant.

2. Processed: foods processed by manufacturers (e.g. processed meat, dairy products) or all foods served at restaurants $\leftarrow$ Salt was added someone other than the participant.

3. Other: any unprocessed ingredients before cooking at home (e.g. vegetables, fish, seasonings used for home-cooking $\leftarrow$ Salt was added by the participant.

Step 2: The categories described in step 1 were rearranged into three groups.

1. Self-cooking: this group includes 'home-made' and 'other' foods.

Salt intake from foods in this group was considered as 'discretionary'.

2. Ready-made: this group includes 'processed' foods consumed at home.

Salt intake from foods in this group was considered as 'non-discretionary'.

3. Dining out: this group includes 'processed' foods consumed outside the home.

Salt intake from foods in this group was considered as 'non-discretionary'.

Fig. 1 Classification of recorded foods by person or entity responsible for salt content

age tertiles, BMI and urinary $\mathrm{Na}$ excretion tertiles. The amount and percentage of energy-adjusted $\mathrm{Na}$ intake from the three intake source groups were also determined to show the ratio between discretionary and non-discretionary $\mathrm{Na}$ intake. Univariate and multivariate linear regression analyses were then performed to examine the effect of age, sex, BMI, energy intake and urinary $\mathrm{Na}$ excretion (actual $\mathrm{Na}$ intake) on the proportion of discretionary $\mathrm{Na}$. In the multivariable model, the prefecture in which a participant lived was also included as a possible confounder. Finally, all recorded foods and beverages were classified into twenty-nine food groups based on the classification in the Standard Tables of Food Composition in Japan ${ }^{(15)}$ to show the proportion of $\mathrm{Na}$ intake from each food group by sex and age. When a certain category in the food composition table included different types of foods (e.g. rice, noodles and bread are included in a 'cereals' category), the classification was performed according to the similarity of nutrient profiles and culinary usage of the food. In these food group categories, the 'other readymade foods' category included processed foods with specific item numbers ${ }^{(15)}$ and hamburgers and fried chicken served at fast-food restaurants, because some of the fast-food restaurants released detailed nutrition facts sheets and nutritional value calculation based on this information was thought to be more accurate than breaking down the food into ingredients before calculation. The relationship between the contribution of each food group to total $\mathrm{Na}$ intake and age was examined using a linear regression model which included the contribution (percentage) of each food group as a dependent variable and age (continuous) as an independent variable.

All analyses were performed with SAS version 9.3. Statistical tests were two-sided and $P$ values of $<0.05$ were considered statistically significant.

\section{Results}

Participant characteristics are shown in Table 1. Each area included about twenty participants, with closely similar numbers by sex and age category due to age and sex stratification at recruitment. Na intake estimated by the DR was lower than $\mathrm{Na}$ excretion assessed by $24 \mathrm{~h}$ urine collection, with a difference between means of $408 \mathrm{mg} / \mathrm{d}$ in men and $303 \mathrm{mg} / \mathrm{d}$ in women.

The amount and proportion of $\mathrm{Na}$ intake from selfcooking, ready-made foods and dining out are described in Table 2. The proportion of discretionary Na intake by self-cooking in total $\mathrm{Na}$ intake was $52.3 \%$ in men and $57.1 \%$ in women. This proportion was apparently lower in younger participants. The proportion of non-discretionary $\mathrm{Na}$ intake by dining out was higher in younger participants, whereas that from ready-made foods was not linearly associated with age. The association between the proportion of discretionary $\mathrm{Na}$ intake and age, sex, BMI, energy intake and $\mathrm{Na}$ excretion as a surrogate of actual $\mathrm{Na}$ intake was assessed by linear regression analysis (Table 3). Older age was significantly associated with a higher proportion of discretionary $\mathrm{Na}$ intake in both men and women $(P<0 \cdot 0001)$. Lower BMI was marginally associated with a higher proportion of discretionary $\mathrm{Na}$ intake in multivariate analysis in women $(P=0.07)$, meaning that under the same age and actual $\mathrm{Na}$ intake, the proportion of discretionary $\mathrm{Na}$ intake was higher in participants with a lower BMI. The proportion of discretionary $\mathrm{Na}$ intake was not significantly different between men and women.

The contribution of each food group to total $\mathrm{Na}$ intake was then examined. Table 4 shows the categorization of all recorded foods and beverages. The greatest contributor was seasonings, which accounted for $61.7 \%$ of total intake in 
Table 1 Characteristics of the study participants: apparently healthy men and women aged 20-69 years, Japan, 2013

\begin{tabular}{|c|c|c|c|c|c|c|}
\hline \multirow[b]{2}{*}{ Variable } & \multicolumn{2}{|c|}{ Men $(n$ 196) } & \multicolumn{2}{|c|}{ Women ( $n$ 196) } & \multicolumn{2}{|c|}{ Total $(n$ 392) } \\
\hline & Mean or $n$ & SD or $\%$ & Mean or $n$ & SD or $\%$ & Mean or $n$ & SD or $\%$ \\
\hline $\begin{array}{l}\text { Age (years), mean and SD } \\
\text { Age group, } n \text { and } \%\end{array}$ & $44 \cdot 6$ & 13.3 & 44.4 & $13 \cdot 5$ & 44.5 & $13 \cdot 4$ \\
\hline $20 \mathrm{~s}$ & 37 & 18.9 & 38 & $19 \cdot 4$ & 75 & $19 \cdot 1$ \\
\hline $30 \mathrm{~s}$ & 42 & 21.4 & 39 & $19 \cdot 9$ & 81 & $20 \cdot 7$ \\
\hline $40 \mathrm{~s}$ & 38 & $19 \cdot 4$ & 41 & $20 \cdot 9$ & 79 & $20 \cdot 2$ \\
\hline $50 \mathrm{~s}$ & 38 & $19 \cdot 4$ & 39 & $19 \cdot 9$ & 77 & $19 \cdot 6$ \\
\hline $60 s$ & 41 & 20.9 & 39 & $19 \cdot 9$ & 80 & $20 \cdot 4$ \\
\hline Body height $(\mathrm{cm})$, mean and SD & $170 \cdot 3$ & 5.4 & $157 \cdot 6$ & $5 \cdot 7$ & 163.9 & 8.4 \\
\hline Body weight $(\mathrm{kg})$, mean and SD & 69.6 & $11 \cdot 3$ & $56 \cdot 1$ & $10 \cdot 0$ & $62 \cdot 9$ & $12 \cdot 6$ \\
\hline BMI $\left(\mathrm{kg} / \mathrm{m}^{2}\right)$, mean and SD & 24.0 & 3.5 & $22 \cdot 6$ & 3.7 & $23 \cdot 3$ & 3.6 \\
\hline SBP $(\mathrm{mmHg})$, mean and SD & $127 \cdot 0$ & $14 \cdot 1$ & $120 \cdot 0$ & 14.9 & 123.5 & 14.9 \\
\hline DBP $(\mathrm{mmHg})$, mean and SD & $80 \cdot 0$ & 11.8 & $76 \cdot 0$ & $10 \cdot 2$ & $78 \cdot 0$ & $11 \cdot 2$ \\
\hline \multicolumn{7}{|l|}{ Past history or current treatment, $n$ and $\%$} \\
\hline Hypertension & 27 & 13.8 & 20 & $10 \cdot 2$ & 47 & $12 \cdot 0$ \\
\hline Hyperlipidaemia & 16 & 8.2 & 20 & $10 \cdot 2$ & 36 & $9 \cdot 2$ \\
\hline Hyperuricaemia & 8 & 4.1 & 1 & 0.5 & 9 & $2 \cdot 3$ \\
\hline Diabetes mellitus & 6 & 3.1 & 2 & 1.0 & 8 & $2 \cdot 0$ \\
\hline Gastric polyp & 5 & $2 \cdot 6$ & 5 & $2 \cdot 6$ & 10 & $2 \cdot 6$ \\
\hline Urinary tract stone & 5 & $2 \cdot 6$ & 0 & 0.0 & 5 & 1.3 \\
\hline Renal dysfunction & 1 & 0.5 & 0 & 0.0 & 1 & 0.3 \\
\hline \multicolumn{7}{|l|}{ Educational background, $n$ and $\%$} \\
\hline Junior high school & 4 & $2 \cdot 0$ & 4 & $2 \cdot 0$ & 8 & $2 \cdot 0$ \\
\hline Senior high school & 38 & $19 \cdot 4$ & 66 & $33 \cdot 7$ & 104 & $26 \cdot 5$ \\
\hline Vocational school or junior college & 56 & 28.6 & 88 & 44.9 & 144 & $36 \cdot 7$ \\
\hline University or graduate school & 98 & $50 \cdot 0$ & 36 & $18 \cdot 4$ & 134 & $34 \cdot 2$ \\
\hline Others & 0 & 0.0 & 2 & 1.0 & 2 & 0.5 \\
\hline \multicolumn{7}{|l|}{ Occupation, $n$ and $\%$} \\
\hline Clerical & 91 & $46 \cdot 4$ & 73 & $37 \cdot 2$ & 164 & 41.8 \\
\hline Nursing care & 77 & 39.3 & 87 & 44.4 & 164 & $41 \cdot 8$ \\
\hline Medical assistant & 4 & $2 \cdot 0$ & 8 & 4.1 & 12 & 3.1 \\
\hline Cooking assistant & 6 & 3.1 & 18 & $9 \cdot 2$ & 24 & $6 \cdot 1$ \\
\hline Others & 18 & $9 \cdot 2$ & 10 & $5 \cdot 1$ & 28 & $7 \cdot 1$ \\
\hline PAL $($ MET $\times h)$, mean and SD & 37.4 & $5 \cdot 8$ & 37.9 & 5.5 & $37 \cdot 6$ & $5 \cdot 6$ \\
\hline \multicolumn{7}{|c|}{ Intake estimated by diet records, mean and SD } \\
\hline Energy $(\mathrm{kJ} / \mathrm{d})$ & 9870 & 2021 & 7902 & 1509 & 8886 & 2038 \\
\hline Protein (\% of energy) & 13.9 & 2.0 & $14 \cdot 3$ & $2 \cdot 0$ & $14 \cdot 1$ & $2 \cdot 0$ \\
\hline Fat (\% of energy) & $27 \cdot 0$ & $5 \cdot 0$ & 29.5 & $5 \cdot 0$ & $28 \cdot 3$ & $5 \cdot 2$ \\
\hline Carbohydrate (\% of energy) & 52.5 & 7.6 & 53.6 & $5 \cdot 3$ & $53 \cdot 1$ & $6 \cdot 6$ \\
\hline Alcohol (\% of energy) & $5 \cdot 1$ & 7.3 & 1.6 & 3.1 & 3.3 & $5 \cdot 8$ \\
\hline $\mathrm{Na}(\mathrm{mg} / \mathrm{d})$ & 4366 & 1137 & 3635 & 1036 & 4000 & 1146 \\
\hline \multicolumn{7}{|l|}{$24 \mathrm{~h}$ urine collection ${ }^{*}$} \\
\hline $\mathrm{Na}$ excretion $(\mathrm{mg} / \mathrm{d})$, mean and SD & 4774 & 1627 & 3938 & 1248 & 4358 & 1508 \\
\hline
\end{tabular}

SBP, systolic blood pressure; DBP, diastolic blood pressure; PAL, physical activity level; MET, metabolic equivalents.

*Urine was successfully collected in 376 participants (189 men and 187 women).

men and $62.9 \%$ in women (Table 5). Soya sauce and miso tended to be consumed by the older participants, while other seasonings including Worcester sauce, dressings and roux tended to be consumed by the younger participants. The second highest contributor was fish and shellfish in both sexes $(6.7 \%$ in men and $6.6 \%$ in women), but the third differed between men (noodles, $4.9 \%$ ) and women (bread, $5.0 \%$ ). The major contributors apart from seasonings also differed by age. For example, the proportion of $\mathrm{Na}$ intake from noodles was significantly larger in younger men ( $P=0.001)$, but this difference was not observed in women $(P=0.63)$. Interestingly, although pickled vegetables are generally considered an important Na source in the Japanese diet, their contribution was only $3.8 \%$ in men and $3.1 \%$ in women, with these proportions being even lower in younger participants $(P<0.0001$ in men, $P=0.02$ in women).

\section{Discussion}

The present study found that the proportion of discretionary $\mathrm{Na}$ intake in total $\mathrm{Na}$ intake was $52.3 \%$ in men and $57 \cdot 1 \%$ in women in Japan. Although this accounted for more than half of intake in both sexes, the significant decrease in discretionary $\mathrm{Na}$ intake in younger generations possibly suggests that the proportion of $\mathrm{Na}$ intake from processed foods and the food-service industry will increase steadily in the Japanese population. The present study was conducted under a cross-sectional design, preventing any direct mention of secular trends in dietary $\mathrm{Na}$ source. Nevertheless, dietary habits established in childhood are known to track into adulthood ${ }^{(28)}$ and this implies that current consumption patterns of salt in young generations will not easily change over time. 
Table 2 Amount and proportion of sodium intake from self-cooking, ready-made foods and dining out, estimated from diet records with consideration to the effect of sex, age, BMI and sodium excretion, in 392 Japanese adults, 2013

\begin{tabular}{|c|c|c|c|c|c|c|c|c|c|c|c|c|c|c|c|c|c|c|c|}
\hline \multirow[b]{4}{*}{ Sex/variable } & \multicolumn{17}{|c|}{ Diet record } & & \\
\hline & \multirow[b]{3}{*}{$n$} & \multirow{2}{*}{\multicolumn{2}{|c|}{ Energy $(\mathrm{kJ} / \mathrm{d})$}} & \multirow{2}{*}{\multicolumn{2}{|c|}{$\begin{array}{c}\text { Crude } \mathrm{Na} \\
\text { intake }(\mathrm{mg} / \mathrm{d}) \\
\text { Total }\end{array}$}} & \multicolumn{12}{|c|}{ Energy-adjusted $\mathrm{Na}$ intake from each intake source group* $(\mathrm{mg} / 4184 \mathrm{~kJ}$ per $\mathrm{d})$} & \multirow{2}{*}{\multicolumn{2}{|c|}{$\begin{array}{c}24 \mathrm{~h} \text { urine } \\
\mathrm{Na} \text { excretiont } \\
(\mathrm{mg} / \mathrm{d})\end{array}$}} \\
\hline & & & & & & \multicolumn{3}{|c|}{ Total } & \multicolumn{3}{|c|}{$\begin{array}{c}\text { Self-cooking } \\
\text { (discretionary intake) }\end{array}$} & \multicolumn{3}{|c|}{$\begin{array}{l}\text { Ready-made (non- } \\
\text { discretionary intake) }\end{array}$} & \multicolumn{3}{|c|}{$\begin{array}{l}\text { Dining out (non- } \\
\text { discretionary intake) }\end{array}$} & & \\
\hline & & Mean & SD & Mean & SD & Mean & SD & $\% \ddagger$ & Mean & SD & $\% \ddagger$ & Mean & SD & $\% \ddagger$ & Mean & SD & $\% \ddagger$ & Mean & SD \\
\hline \multicolumn{20}{|l|}{ Men } \\
\hline $\begin{array}{l}\text { All } \\
\text { Age (years) }\end{array}$ & 196 & 9870 & 2021 & 4366 & 1137 & 1867 & 374 & 100 & 979 & 488 & $52 \cdot 3$ & 323 & 288 & $17 \cdot 2$ & 565 & 405 & $30 \cdot 6$ & 4774 & 1627 \\
\hline Low (range: $21-36$ ) & 64 & 9662 & 2332 & 4170 & 1107 & 1840 & 400 & 100 & 849 & 552 & 46.2 & 330 & 353 & $17 \cdot 8$ & 661 & 481 & 36.0 & 4601 & 1638 \\
\hline Middle (range: 37-52) & 64 & 9882 & 1671 & 4260 & 990 & 1807 & 324 & 100 & 940 & 421 & $51 \cdot 7$ & 285 & 253 & $15 \cdot 4$ & 582 & 349 & 32.9 & 4833 & 1401 \\
\hline High (range: 53-69) & 68 & 10054 & 2018 & 4650 & 1248 & 1949 & 384 & 100 & 1139 & 443 & 58.4 & 352 & 248 & $18 \cdot 2$ & 458 & 353 & $23 \cdot 3$ & 4884 & 1829 \\
\hline \multicolumn{20}{|l|}{$\mathrm{BMI}\left(\mathrm{kg} / \mathrm{m}^{2}\right)$} \\
\hline Normal $(<25)$ & 135 & 9891 & 1802 & 4317 & 948 & 1847 & 361 & 100 & 977 & 495 & 52.5 & 325 & 312 & $17 \cdot 4$ & 544 & 383 & $30 \cdot 1$ & 4516 & 1380 \\
\hline Overweight $(\geq 25)$ & 61 & 9823 & 2454 & 4472 & 1476 & 1913 & 402 & 100 & 984 & 476 & $51 \cdot 7$ & 317 & 228 & $16 \cdot 6$ & 611 & 449 & 31.7 & 5315 & 1955 \\
\hline \multicolumn{20}{|l|}{$\mathrm{Na}$ excretiont $(\mathrm{mg} / \mathrm{d})$} \\
\hline Low (range:1536-3959) & 63 & 9710 & 1742 & 4120 & 884 & 1791 & 334 & 100 & 924 & 442 & 51.6 & 270 & 196 & $15 \cdot 3$ & 597 & 414 & 33.1 & 3204 & 578 \\
\hline Medium (3973-5078) & 63 & 10104 & 2112 & 4176 & 1037 & 1747 & 333 & 100 & 881 & 461 & $50 \cdot 3$ & 325 & 255 & 18.5 & 541 & 392 & $31 \cdot 2$ & 4505 & 344 \\
\hline High (5103-11 076) & 63 & 9976 & 2023 & 4827 & 1294 & 2032 & 383 & 100 & 1129 & 521 & $55 \cdot 4$ & 323 & 291 & $15 \cdot 7$ & 581 & 419 & $28 \cdot 9$ & 6613 & 1247 \\
\hline \multicolumn{20}{|l|}{ Women } \\
\hline \multicolumn{10}{|l|}{ Age (years) } & 550 & $57 \cdot 1$ & 303 & 232 & $16 \cdot 1$ & 507 & 348 & $26 \cdot 8$ & & 1248 \\
\hline Low (range: $20-36$ ) & 66 & 7678 & 1482 & 3502 & 983 & 1926 & 491 & 100 & 982 & 536 & $50 \cdot 4$ & 325 & 270 & $17 \cdot 0$ & 620 & 358 & $32 \cdot 6$ & 3788 & 1186 \\
\hline Middle (range: $37-53$ ) & 66 & 7980 & 1446 & 3460 & 863 & 1821 & 370 & 100 & 1085 & 460 & 58.5 & 259 & 199 & 14.6 & 477 & 278 & $26 \cdot 8$ & 3818 & 1137 \\
\hline High (range: 54-69) & 64 & 8052 & 1596 & 3952 & 1183 & 2061 & 471 & 100 & 1314 & 601 & 62.6 & 325 & 218 & $16 \cdot 5$ & 422 & 375 & $20 \cdot 8$ & 4222 & 1389 \\
\hline \multicolumn{20}{|l|}{ BMI $\left(\mathrm{kg} / \mathrm{m}^{2}\right)$} \\
\hline Normal $(<25)$ & 160 & 7840 & 1445 & 3582 & 979 & 1924 & 451 & 100 & 1113 & 521 & $57 \cdot 2$ & 298 & 234 & $15 \cdot 7$ & 513 & 353 & $27 \cdot 1$ & 3796 & 1114 \\
\hline Overweight $(\geq 25)$ & 36 & 8177 & 1765 & 3867 & 1247 & 1983 & 476 & 100 & 1177 & 668 & 57.0 & 322 & 228 & $17 \cdot 4$ & 483 & 328 & $25 \cdot 6$ & 4678 & 1623 \\
\hline \multicolumn{20}{|l|}{$\mathrm{Na}$ excretiont (mg/d) } \\
\hline Low (range: 1288-3275) & 62 & 7594 & 1279 & 3273 & 798 & 1811 & 354 & 100 & 1007 & 409 & $55 \cdot 3$ & 254 & 184 & $14 \cdot 2$ & 550 & 347 & 30.5 & 2727 & 426 \\
\hline Medium (3279-4250) & 63 & 8135 & 1478 & 3674 & 912 & 1905 & 440 & 100 & 1116 & 559 & 57.4 & 323 & 246 & 17.7 & 465 & 341 & $25 \cdot 0$ & 3781 & 272 \\
\hline High (4271-9655) & 62 & 8047 & 1525 & 3972 & 1092 & 2086 & 519 & 100 & 1236 & 618 & 58.4 & 340 & 257 & $16 \cdot 7$ & 510 & 354 & $24 \cdot 9$ & 5307 & 1035 \\
\hline
\end{tabular}

*Mean daily $\mathrm{Na}$ intake was estimated by the $4 \mathrm{~d}$ diet record. Both crude and energy-adjusted intakes by the density method are shown.

$\dagger \mathrm{Na}$ excretion was measured by $24 \mathrm{~h}$ urine collection in 376 participants (189 men and 187 women).

$\ddagger$ The percentage indicates the proportion of $\mathrm{Na}$ intake from each intake source group in total $\mathrm{Na}$ intake. 
Table 3 Association between age, BMI, urinary sodium excretion, energy intake and proportion of discretionary sodium intake (sodium intake from self-cooking dishes and foods; \%) by univariate and multivariate linear regression analysis in 376 Japanese adults, 2013

\begin{tabular}{|c|c|c|c|c|c|c|}
\hline \multirow[b]{2}{*}{ Sex } & \multirow[b]{2}{*}{$n$} & \multirow[b]{2}{*}{ Variable } & \multicolumn{2}{|c|}{ Univariate model ${ }^{*}$} & \multicolumn{2}{|c|}{ Multivariate model $^{\star}$} \\
\hline & & & Regression coefficient & $P$ value & Regression coefficient & $P$ value \\
\hline \multirow[t]{4}{*}{ Men } & 189 & Age (years) & 0.46 & $<0.0001$ & 0.45 & $<0.0001$ \\
\hline & & BMI $\left(\mathrm{kg} / \mathrm{m}^{2}\right)$ & -0.15 & 0.72 & -0.11 & 0.81 \\
\hline & & $\mathrm{Na}$ excretion (mg/d) & 0.0014 & 0.14 & 0.00081 & 0.37 \\
\hline & & Energy intake $(\mathrm{kJ} / \mathrm{d})$ & 0.0015 & 0.04 & 0.0013 & 0.08 \\
\hline \multirow[t]{4}{*}{ Women } & 187 & Age (years) & 0.41 & 0.0001 & 0.50 & $<0.0001$ \\
\hline & & BMI $\left(\mathrm{kg} / \mathrm{m}^{2}\right)$ & -0.29 & 0.51 & -0.90 & 0.07 \\
\hline & & $\mathrm{Na}$ excretion (mg/d) & 0.0013 & 0.26 & 0.00098 & 0.46 \\
\hline & & Energy intake $(\mathrm{kJ} / \mathrm{d})$ & -0.0013 & 0.20 & -0.0017 & 0.12 \\
\hline \multirow[t]{5}{*}{ All } & 376 & Sex (reference: women) & $-3 \cdot 0$ & 0.15 & -3.9 & 0.10 \\
\hline & & Age (years) & 0.44 & $<0.0001$ & 0.44 & $<0.0001$ \\
\hline & & $\mathrm{BMI}\left(\mathrm{kg} / \mathrm{m}^{2}\right)$ & -0.31 & 0.30 & -0.51 & 0.10 \\
\hline & & $\mathrm{Na}$ excretion (mg/d) & 0.0010 & 0.16 & 0.00091 & 0.22 \\
\hline & & Energy intake $(\mathrm{kJ} / \mathrm{d})$ & 0.000034 & 0.95 & 0.0005 & 0.46 \\
\hline
\end{tabular}

Age, BMI, urinary $\mathrm{Na}$ excretion and energy intake were individually included as independent variables in the univariate model.

Age, BMI, urinary $\mathrm{Na}$ excretion, energy intake and residential prefecture (twenty study areas) were simultaneously included in the multivariable model.

In the analysis including both men and women, sex was included as another independent variable in the multivariate model.

${ }^{*}$ In the linear regression analysis, the proportion of discretionary $\mathrm{Na}$ intake (\%) was the dependent variable.

Several studies from Asian ${ }^{(14,19,21)}$, South American ${ }^{(20,22)}$ and African ${ }^{(20)}$ countries have reported that a high proportion of $\mathrm{Na}$ intake comes from discretionary sources or seasonings, while studies in European ${ }^{(14,17)}$ and North American $^{(14,18)}$ countries have reported that a high proportion is non-discretionary or from processed foods. Although Japan is an Asian country, efforts to reduce salt intake will need to be made at not only the personal level but also by the food-service industry, by reducing the salt content of processed foods and in dishes.

BMI was not associated with the proportion of discretionary $\mathrm{Na}$ intake in men. Although we previously reported that higher BMI was associated with higher $\mathrm{Na}$ excretion (i.e. absolute amount of $\mathrm{Na}$ intake) ${ }^{(11)}$, the source of $\mathrm{Na}$ in the present study was the same regardless of body constitution. On the other hand, higher BMI was marginally associated with a lower proportion of discretionary $\mathrm{Na}$ intake in women on multivariate analysis. As the self-reported frequency of dining out was not significantly related with BMI in women (data not shown), food selection or use of salty seasonings (or both) might differ between individuals with high and low BMI. Our previous study showed that although both $\mathrm{Na}$ and $\mathrm{K}$ intakes were significantly higher in individuals with a higher BMI, the increment of mean $\mathrm{K}$ intake in these individuals was relatively smaller than that of mean $\mathrm{Na}$ intake $^{(11)}$. We speculated that individuals with a higher BMI tended to have an unhealthy lifestyle, such as a preference for salty foods and aversion to foods with high $\mathrm{K}$ content ${ }^{(11)}$. The marginal relationship between higher $\mathrm{BMI}$ and a lower proportion of discretionary $\mathrm{Na}$ intake observed in the present study might support our previous speculation, because a higher proportion of discretionary $\mathrm{Na}$ intake might have reflected a lower intake of $\mathrm{Na}$ from processed foods or the food-service industry based on health-consciousness. In any case, these behavioural aspects of salt intake should be clarified in future studies. The difference in results between men and women might have resulted from the fact that women are usually in charge of meal preparation in Japan ${ }^{(29)}$. Na sources in men might be largely affected by the women who prepare the meals for them. In men, a marginal $(P=0.08)$ and positive relationship was observed between energy intake and the proportion of discretionary $\mathrm{Na}$ intake. This was possibly due to difficulty of accurately reporting of foods consumed out of home, but an exact reason was unknown.

Further, Na excretion was not associated with the proportion of discretionary $\mathrm{Na}$ intake in both men and women. This result implies that both discretionary and non-discretionary $\mathrm{Na}$ intakes were higher in those who consumed a higher amount of $\mathrm{Na}$, and that the ratio between them was stable. Both individual and population approaches to salt reduction should be implemented for all people, regardless of their $\mathrm{Na}$ consumption.

The difference in food groups contributing to $\mathrm{Na}$ intake between age categories was also notable. The greatest contributor to $\mathrm{Na}$ intake was seasonings and the proportion of $\mathrm{Na}$ from seasonings was distributed in a narrow range (58.8-65.5\%), even in the different sexes and age categories. A decrease in salty seasoning use and/or promotion of the use of salt-reduced seasonings would also be effective in reducing salt intake in the whole Japanese population. In contrast, other food groups contributing to $\mathrm{Na}$ intake differed between sexes and age categories. The second contributor was fish and shellfish in both sexes, but their contribution was significantly smaller in younger participants. Instead, the contribution of meat to $\mathrm{Na}$ intake was significantly greater in younger participants. Other important contributors to $\mathrm{Na}$ intake were noodles and bread. Their total proportion as 


\begin{tabular}{ll} 
Food group & Representative foods \\
\hline $\begin{array}{l}\text { Well-milled rice } \\
\text { Other rice and grains }\end{array}$ & Well-milled rice \\
& Brown rice, half-milled rice, oats, barley, rye, corn, wheat (whole grain) \\
Noodles & Japanese noodles, Chinese noodles, macaroni and spaghetti \\
Bread & White table bread, soft rolls, croissants \\
Other grain products & Wheat flour, fu (gluten products), chio tzu pastry (skin of dumpling), \\
& pizza crust, cornflakes \\
Potatoes & Potatoes, sweet potatoes, Japanese yam, French fries \\
Sugar & Brown sugar lump, soft sugars, honey, strawberry jams, orange marmalade \\
Pulses & Adzuki beans, kidney beans, peas, soyabeans and their \\
Nuts & products (tofu, natto) \\
Green and yellow vegetables† & Almonds, chestnuts, walnuts, peanuts \\
& Asparagus, okra, pumpkin, tomatoes, Chinese chive, carrot, parsley,
\end{tabular}

Green and yellow vegetablest Asparagus, okra, pumpkin, tomatoes, Chinese chive, carrot, parsley, green sweet peppers, broccoli, spinach, Brussels sprouts

Pickled vegetables $\dagger$

Salted pickles of Japanese apricots, salted pickles of cucumber, pickles of Japanese radish (nukamiso-zuke, takuan-zuke), pickles of eggplants (karashi-zuke, shiba-zuke)

Other vegetables

Fruits

Fruit and vegetable juice

Mushrooms

Seaweeds

Fish and shellfish

Meat

Eggs

Dairy products

Fats

Oils

Confectioneries

Alcohol beverages

Tea and coffee

Soft drinks

Turnip, cauliflower, cabbage, cucumber, ginger, zucchini, celery, Japanese radish (root), onion, eggplant, Chinese cabbage

Strawberries, satsuma mandarins, oranges, Japanese persimmons, cherries, Japanese pears, bananas, grapes, melons, apples, lemons

Straight fruit juice and reconstituted fruit juice of satsuma mandarins, Valencia orange, grapefruit, pineapple, grape and apple

Winter mushrooms, shiitake, bunashimeji (brown beech mushroom), common mushrooms

Purple laver, ma-kombu (kelp), hijiki, wakame

Horse mackerel, sardines, salmons, tunas, shrimps, crabs, squids, fish paste products

Beef, pork, ham, bacon, chicken

Japanese quail's eggs, hen's eggs

Ordinary liquid milk, whole milk powder, cream, yoghurt, natural cheese processed cheese

Lard, butters

Olive oil, sesame oil, rapeseed oil, margarines, shortening, mayonnaise Manju (baked or steamed dough stuffed with filling), amedama (drops), rice crackers, bean jam bun, sponge cake, doughnuts, biscuits, milk chocolate, chewing gums, ice cream

Sake, beer, wine, whisky, mirin

Green teas, oolong tea, black tea, coffee, cocoa

$50 \%$ fruit juice beverage (Valencia orange, pineapple), lactic acid
Item number in the Standard Tables of Food Composition in Japan ${ }^{(15)}$ corresponding to included foods

1083, 1088, 1093, 1097, 1101, 1105, 1109-1114, 1117, 1118

$1001-1007,1010-1014,1080-1082,1084-1087,1089-1092,1094-1096$ 1098-1100, 1102-1104, 1106-1108, 1131-1134, 1138-1142

1008-1009, 1038-1064, 1115, 1122-1130

$1026-1037$

1015-1023, 1025, 1065-1079, 1116, 1119-1121, 1137, 1143, 15035

2001-2040

3001-3023, 7010-7011, 7013-7014, 7046-7047, 7123, 7125, 7154

$1118^{\star}, 4001-4005,4007-4013,4016-4019,4021-4073$

$5001-5037$

6003-6011, 6018-6021, 6027-6028, 6030-6035, 6046-6050, 6052, 6071-6073, 6075-6077, 6080, 6083, 6086-6087, 6089-6090, 6093-6100, 6113-6114

6117-6118, 6126-6128, 6130-6131, 6144-6145, 6147, 6157-6158,

6160-6166, 6169-6172, 6182-6184, 6188-6190, 6200-6204, 6207-6209,

6211-6216, 6218-6222, 6224-6225, 6227-6229, 6232, 6237-6239,

6245-6248, 6251-6252, 6254, 6261-6264, 6267-6269, 6272, 6274-6279,

6283-6285, 6293-6294, 6298-6302, 6308-6309, 6313-6315, 6319-6321

(Green and yellow) 6029, 6040, 6043, 6053, 6074, 6091, 6115, 6146, 6148, 6230-6231, 6253, 6255, 6273

(Other) 7019-7024, 7037-7039; 6041, 6042, 6044-6045, 6066-6070, 6088 6104-6105, 6107-6108, 6137-6143, 6195-6199, 6235-6236, 6242, 6295 6306, 6323

Vegetables with item number of 6000 s, which are included in neither green and yellow vegetables nor pickled vegetables bacteria beverages, fruit-flavoured and coloured drink, cola drink
$7001-7003,7005-7009,7012,7015-7018,7026-7029,7035-7036,7040-7041$ 7048-7057, 7060-7062, 7067-7075, 7077-7097, 7102-7117, 7122, 7124, $7126-7136,7138-7148,7153,7155-7158$

6185-6186, 6217, 7030-7032, 7042-7043, 7063-7064, 7098-7099, 7118-7119, $7149-7150$

8001-8036

9001-9047

$10001-10388$

$11001-11244$

$12001-12020$

$13001-13027,13031-13041,13048,13050-13052$

$14015-14019$

14 001-14 014, 14 020-14 022, 17 040-17 043

$1024,1135-1136,4006,4014-4015,4020,13042-13047,13049$

$15001-15034,15036-15120$

$16001-16032$

$16033-16049,16051,16055$

7004, 7025, 7033-7034, 7044-7045, 7058-7059, 7065-7066, 70 776, 7100-7101, $7120-7121,7137,7151-7152,13028-13030,16050,16052-16054$ 
Na source was approximately $8-9 \%$, a larger proportion than that from fish and shellfish. Although rice is a staple food in Japan, other processed foods which are consumed as staples in large quantities cannot be ignored as important $\mathrm{Na}$ sources. If $\mathrm{Na}$ content reduction is to be implemented in Japan, good candidates include bread, noodles and processed meats, as they are already considered in the $\mathrm{UK}^{(5)}$. Traditional salty foods such as pickled vegetables and miso soup have attracted attention as the main contributors to salt intake in Japan and a reduction in their intake is frequently recommended. However, pickled vegetables accounted for approximately $2 \%$ of total $\mathrm{Na}$ intake in participants aged less than 36 years and lists of the major $\mathrm{Na}$ sources in the Japanese diet should be adjusted accordingly.

It is difficult to compare our results about the contribution of food groups to total $\mathrm{Na}$ intake with the INTERMAP study because categorization of the food groups was considerably different and a list of food codes included in each food group was not shown in the INTERMAP study ${ }^{(14)}$. The contribution of soya sauce was almost the same in two studies, but that of salted vegetables and fruits was largely different $(9.8 \%$ in the INTERMAP, $3.8 \%$ in men and $3.1 \%$ in women in our study) ${ }^{(14)}$. The reasons for the difference might be the difference in participants' age (40-59 years in the INTERMAP and 20-69 years in our study) and timing of implementation of the studies. Also, when the amounts of ingredients were clear, home-made salted vegetables in our study were broken down into ingredients (salt and raw vegetables) before the coding to estimate salt intake precisely. If all salted vegetables recorded in the INTERMAP study were given the food codes for the typical salted vegetables in the food composition table ${ }^{(15)}$, their contribution should have been higher than that in our study. Making salted vegetables at home can be considered a cooking process such as baking or stewing, so it is difficult to determine which coding method is better.

From a different viewpoint, our present results imply that dietary habits in Japan are in a process of nutrition transition $^{(30-32)}$. Since the present study was a crosssectional one, little can be said about secular trends in dietary intake within individuals. However, another recent study showed similar changes in food intake, namely recently increasing intakes of meats and confectioneries in younger individuals and increasing intakes of fish and fruits in older age ${ }^{(33)}$. Unlike most studies of nutrition transition ${ }^{(30-32)}$, we did not describe changes in fat, sugar and fibre intakes between generations, but the increased $\mathrm{Na}$ intake from processed foods (e.g. noodles, bread) and meats and the lower intake from fish and traditional pickled vegetables in our younger participants implies that the Westernization of dietary patterns in Japanese is progressing. These changes in food consumption pattern should be considered in efforts to reduce salt intake not only in Japan but also in other countries facing a rapid 
Table 5 Sodium intake from each food group and their contribution as sodium sources in 392 Japanese adults, 2013; difference between age categories

\begin{tabular}{|c|c|c|c|c|c|c|c|c|c|c|c|c|}
\hline \multirow{3}{*}{$\begin{array}{l}\text { Food group } \\
\text { Age (years) }\end{array}$} & \multicolumn{6}{|c|}{ Men } & \multicolumn{6}{|c|}{ Women } \\
\hline & \multirow{2}{*}{$\begin{array}{c}\begin{array}{c}\text { Intake } \\
(\mathrm{mg} / \mathrm{d})\end{array} \\
\text { All }\end{array}$} & \multicolumn{4}{|c|}{ Contribution (\%)* } & \multirow[b]{2}{*}{$\begin{array}{c}P \text { for } \\
\text { trend } \dagger\end{array}$} & \multirow{2}{*}{$\begin{array}{c}\begin{array}{c}\text { Intake } \\
(\mathrm{mg} / \mathrm{d})\end{array} \\
\text { All }\end{array}$} & \multicolumn{4}{|c|}{ Contribution $(\%)^{*}$} & \multirow[b]{2}{*}{$\begin{array}{l}P \text { for } \\
\text { trend } †\end{array}$} \\
\hline & & All & $\begin{array}{c}\text { Low (range: } \\
21-36)\end{array}$ & $\begin{array}{l}\text { Middle (range: } \\
37-52)\end{array}$ & $\begin{array}{c}\text { High (range: } \\
53-69)\end{array}$ & & & All & $\begin{array}{l}\text { Low (range: } \\
20-36 \text { ) }\end{array}$ & $\begin{array}{l}\text { Middle (range: } \\
37-53 \text { ) }\end{array}$ & $\begin{array}{c}\text { High (range: } \\
54-69)\end{array}$ & \\
\hline$n$ & 196 & 196 & 64 & 64 & 68 & & 196 & 196 & 66 & 66 & 64 & \\
\hline Well-milled rice & $15 \cdot 8$ & 0.41 & 0.37 & 0.54 & 0.32 & 0.38 & $12 \cdot 1$ & 0.33 & 0.30 & 0.46 & 0.24 & 0.82 \\
\hline Other rice and grains & 0.1 & 0.00 & 0.00 & 0.00 & 0.00 & 0.32 & 0.0 & 0.00 & 0.00 & 0.00 & 0.00 & 0.52 \\
\hline Noodles & $207 \cdot 7$ & 4.92 & 7.38 & 4.42 & 3.06 & 0.001 & $107 \cdot 1$ & $2 \cdot 87$ & 3.22 & $2 \cdot 44$ & 2.95 & 0.63 \\
\hline Bread & 176.4 & $4 \cdot 26$ & $3 \cdot 16$ & 4.97 & 4.62 & 0.02 & $169 \cdot 8$ & $5 \cdot 00$ & $5 \cdot 10$ & 5.49 & $4 \cdot 39$ & 0.31 \\
\hline Other grain products & 14.0 & 0.35 & 0.41 & 0.45 & 0.20 & 0.11 & 11.4 & 0.31 & 0.37 & 0.27 & 0.29 & 0.43 \\
\hline Potatoes & 3.8 & 0.09 & 0.13 & $0 \cdot 11$ & 0.04 & 0.09 & 3.3 & $0 \cdot 10$ & $0 \cdot 14$ & 0.09 & 0.06 & 0.35 \\
\hline Sugar & 0.4 & 0.01 & 0.01 & 0.01 & 0.01 & 0.09 & 0.4 & 0.01 & 0.01 & 0.01 & 0.01 & 0.88 \\
\hline Pulses & $15 \cdot 8$ & 0.38 & 0.40 & 0.30 & 0.43 & 0.39 & 13.9 & 0.40 & 0.35 & 0.41 & 0.44 & 0.59 \\
\hline Nuts & $2 \cdot 7$ & 0.06 & 0.04 & 0.09 & 0.04 & 0.91 & 1.7 & 0.04 & 0.04 & 0.05 & 0.04 & 0.88 \\
\hline Green and yellow vegetables & $16 \cdot 0$ & 0.37 & 0.44 & 0.35 & 0.33 & 0.29 & $16 \cdot 5$ & 0.45 & 0.47 & 0.49 & 0.39 & 0.98 \\
\hline Pickled vegetables & 184.9 & 3.83 & 2.02 & 2.78 & 6.52 & $<0.0001$ & $126 \cdot 2$ & $3 \cdot 11$ & $2 \cdot 30$ & $3 \cdot 12$ & 3.95 & 0.02 \\
\hline Other vegetables & $12 \cdot 4$ & 0.28 & 0.30 & 0.29 & 0.27 & 0.43 & $14 \cdot 4$ & 0.39 & 0.35 & 0.39 & 0.44 & $0 \cdot 11$ \\
\hline Fruits & 0.4 & 0.010 & 0.008 & 0.010 & 0.013 & 0.02 & 0.6 & 0.017 & 0.010 & 0.013 & 0.027 & $<0.0001$ \\
\hline Fruit and vegetable juice & $16 \cdot 0$ & 0.37 & 0.30 & 0.37 & 0.43 & 0.82 & $10 \cdot 2$ & 0.28 & 0.36 & 0.20 & 0.29 & 0.39 \\
\hline Mushrooms & 2.4 & 0.05 & 0.02 & 0.06 & 0.08 & 0.20 & 2.6 & 0.07 & 0.05 & 0.09 & 0.07 & 0.67 \\
\hline Seaweeds & 68.6 & 1.56 & 1.02 & 1.85 & 1.79 & 0.09 & 70.5 & 1.87 & 1.51 & 1.41 & $2 \cdot 73$ & 0.003 \\
\hline Fish and shellfish & 298.5 & $6 \cdot 67$ & $5 \cdot 62$ & $6 \cdot 26$ & 8.03 & 0.002 & $246 \cdot 3$ & 6.58 & $5 \cdot 74$ & $6 \cdot 01$ & 8.03 & 0.004 \\
\hline Meat & $167 \cdot 0$ & $3 \cdot 88$ & $4 \cdot 36$ & 3.80 & 3.49 & 0.01 & $120 \cdot 8$ & 3.56 & 4.09 & 3.76 & 2.79 & 0.003 \\
\hline Eggs & 63.0 & 1.50 & 1.51 & 1.53 & 1.46 & 0.92 & 50.5 & 1.45 & 1.46 & 1.48 & 1.41 & 0.73 \\
\hline Dairy products & 83.1 & 1.98 & $2 \cdot 17$ & 1.80 & 1.97 & 0.55 & 89.8 & 2.59 & 2.49 & $2 \cdot 77$ & 2.52 & 0.69 \\
\hline Fats & $7 \cdot 3$ & 0.18 & 0.15 & 0.20 & 0.18 & 0.98 & 8.7 & 0.25 & 0.28 & $0 \cdot 17$ & 0.29 & 0.84 \\
\hline Oils & $55 \cdot 1$ & 1.31 & 1.38 & 1.37 & $1 \cdot 18$ & 0.28 & 53.2 & 1.57 & 1.62 & 1.89 & 1.17 & 0.07 \\
\hline Confectioneries & $65 \cdot 6$ & 1.54 & 1.83 & 1.36 & 1.45 & 0.23 & $76 \cdot 8$ & $2 \cdot 22$ & 2.66 & $2 \cdot 25$ & 1.75 & 0.01 \\
\hline Alcohol beverages & 4.2 & $0 \cdot 10$ & 0.08 & 0.11 & 0.10 & 0.51 & 1.4 & 0.04 & 0.03 & 0.06 & 0.04 & 0.26 \\
\hline Tea and coffee & 21.7 & 0.53 & 0.60 & 0.65 & 0.35 & 0.05 & 18.4 & 0.53 & 0.51 & 0.53 & 0.57 & 0.52 \\
\hline Soft drinks & 1.6 & 0.03 & 0.03 & 0.04 & 0.03 & 0.22 & 1.9 & 0.06 & 0.07 & 0.04 & 0.06 & 0.31 \\
\hline Seasonings, totalł & 2714.0 & $61 \cdot 7$ & 61.5 & $62 \cdot 2$ & 61.5 & 0.99 & 2304.1 & 62.9 & 62.7 & 62.7 & 63.2 & 0.82 \\
\hline Seasonings, soya sauces & $867 \cdot 2$ & $19 \cdot 6$ & 19.2 & $18 \cdot 8$ & $20 \cdot 9$ & 0.24 & $750 \cdot 1$ & $20 \cdot 0$ & $18 \cdot 8$ & $18 \cdot 9$ & $22 \cdot 3$ & 0.02 \\
\hline Seasonings, miso & $402 \cdot 6$ & 9.01 & 7.64 & 8.64 & $10 \cdot 65$ & 0.007 & $349 \cdot 3$ & 9.34 & 8.81 & 8.29 & 10.95 & 0.09 \\
\hline Seasonings, salt & 696.5 & $16 \cdot 0$ & 15.9 & $17 \cdot 7$ & 14.5 & 0.24 & 592.7 & $16 \cdot 4$ & $17 \cdot 1$ & $17 \cdot 4$ & 14.7 & 0.23 \\
\hline Seasonings, soup stock & 278.6 & $6 \cdot 33$ & $7 \cdot 10$ & 5.92 & 6.00 & 0.25 & $253 \cdot 1$ & 6.92 & $6 \cdot 81$ & 7.55 & $6 \cdot 37$ & 0.27 \\
\hline Seasonings, others & 469.2 & $10 \cdot 7$ & 11.6 & $11 \cdot 1$ & 9.5 & $0 \cdot 16$ & 358.8 & $10 \cdot 2$ & 11.2 & $10 \cdot 6$ & 8.8 & 0.03 \\
\hline Other ready-made foods & 144.6 & 3.56 & 4.70 & 4.00 & 2.06 & 0.002 & 101.3 & 3.00 & 3.74 & 3.36 & 1.88 & 0.04 \\
\hline Supplements & 2.4 & 0.06 & 0.03 & 0.10 & 0.05 & 0.87 & 0.6 & 0.02 & 0.01 & 0.03 & 0.01 & 0.87 \\
\hline
\end{tabular}

${ }^{*}$ Contribution (\%) of each food group as Na source in total Na intake.

†Trend of association was examined using a linear regression model including the contribution (\%) as a dependent variable and the age (continuous) as an independent variable.

f'Seasoning, total' is the sum of seasonings in five categories (soya sauces, miso, salt, soup stock and others). 
change in dietary habits. Further, given the impact of increasing intakes of fat and sugar and decreasing intake of high-fibre foods, as well as higher intake of $\mathrm{Na}$, which are all important risk factors for non-communicable diseases $^{(31,32)}$, these changes indicate the need for a more comprehensive reconsideration of dietary intake.

Another important finding of the present study is that estimation of the absolute amount of $\mathrm{Na}$ intake using the DR was inaccurate. An inconsistency between intake estimated by the DR and excretion measured by $24 \mathrm{~h}$ urine collection was apparent in participants with particularly high or low $\mathrm{Na}$ intake. Pearson correlation coefficients between the crude estimated and crude measured values were $0.35(P<0.0001)$ in men and $0.40(P<0.0001)$ in women, indicating reasonably good correlation. In contrast, differences between the means of measured and estimated values per measured $\mathrm{Na}$ excretion in the male participant groups with low, medium and high $\mathrm{Na}$ excretion were $28.6 \%$ (over-reporting), $-7.3 \%$ (underreporting) and $-27 \cdot 1 \%$ (under-reporting), respectively. Similar results were seen in the female participants. Thus, estimated $\mathrm{Na}$ intake appeared higher than actual intake in participants with low $\mathrm{Na}$ intake, and lower than actual intake in those with high $\mathrm{Na}$ intake. When information about the amount of food items consumed was approximate only, we had to use standardized weights for some foods based on a book detailing the effect of cooking on ingredients or the amount of seasonings including in typical Japanese dishes ${ }^{(34)}$. For raw tuna sushi, for example, one dip of soya sauce was defined as $0.12 \mathrm{~g}$ when the participant reported using a 'small amount' of soya sauce or $0.25 \mathrm{~g}$ when using a 'large amount'. This standardization process might have masked extreme amounts of consumed foods, resulting in convergence of estimated intakes to the average. Moreover, the effect of this standardization was probably greater for seasonings than for other foods, because it is difficult to record their precise amount, with consumption often less than $10 \mathrm{~g}$. At the same time, misreporting of overall foods and beverages should be considered in interpreting the results. Zhang et al. reported that people with a higher BMI tend to under-report both $\mathrm{Na}$ as well as energy intakes ${ }^{(35)}$ and used the ratio of the dietary intake of $\mathrm{Na}$ to urinary $\mathrm{Na}$ excretion as a biomarker of under-reporting of energy. Further, Murakami et al. reported that $\mathrm{Na}$ intake was under-reported in under-reporters of energy intake, but that energy-adjusted intake of $\mathrm{Na}$ did not differ between under-reporters, acceptable reporters and over-reporters ${ }^{(36)}$. Here, therefore, we focused on the proportion of $\mathrm{Na}$ intake from various sources in total estimated $\mathrm{Na}$ intake.

Our study has several strengths. First, as the survey was designed from the outset to collect information about salt intake, the DR was designed to collect detailed information about seasoning and salty foods. Precise information, such as the brand name of individual seasonings or consumed amount, was useful in estimating $\mathrm{Na}$ intake, because most $\mathrm{Na}$ contained in foods is invisible. The classification of $\mathrm{Na}$ source, in particular the categories used to define discretionary and non-discretionary intake, were also planned before the survey was started and categorization was performed systematically. Three studies have reported the contribution of food groups as $\mathrm{Na}$ sources in the Japanese diet, but none of them classified $\mathrm{Na}$ intake into discretionary and non-discretionary intake $^{(12-14)}$. Second, salt intake estimated by the DR and $\mathrm{Na}$ excretion measured by $24 \mathrm{~h}$ urine collection could be matched. This allowed us to determine the degree of misreporting in the DR and to compare the proportion of discretionary intake between participants with high $\mathrm{Na}$ intake, which were accurately evaluated using the $24 \mathrm{~h}$ urine collection, and those with low $\mathrm{Na}$ intake. Lastly, the survey was conducted in both men and women in wide range of age groups (20-69 years) living throughout Japan. The difference in $\mathrm{Na}$ sources between generations was clearly described and should be considered in establishing salt reduction programmes for the entire population.

On the other hand, several limitations of the study should be noted. First, the participants were not randomly sampled from the general Japanese population, but were volunteers and likely health-conscious. All except those aged 60 years and above were recruited from welfare facilities. As stated in our previous study ${ }^{(11)}$, however, the basic characteristics of the participants were similar to those of the general Japanese population. Second, as described above, considerable misreporting in the DR was still observed, and Na intake was particularly under- or overestimated in participants whose $\mathrm{Na}$ intake was particularly high or low. Thus, we mainly discuss the proportion of $\mathrm{Na}$ intake from various sources, not the amount. Third, classification of food groups was difficult. We had to use a surrogate food item number for some processed foods or break them down into ingredients when they were not assigned a special food item number in the Standard Tables of Food Composition in Japan ${ }^{(15)}$. This might have caused misclassification, particularly for the 'other ready-made foods' category. However, as a source of $\mathrm{Na}$ in the present study, the contribution of this category was not particularly large, at 3.6\% in men and $3.0 \%$ in women.

\section{Conclusion}

In conclusion, we examined $\mathrm{Na}$ sources in the Japanese diet. The proportion of discretionary $\mathrm{Na}$ intake was $52.3 \%$ in men and $57.1 \%$ in women. Since $\mathrm{Na}$ intake from processed foods and the food-service industry was larger in the younger participants, a population approach to $\mathrm{Na}$ reduction will become increasingly important.

\section{Acknowledgements}

Acknowledgements: The authors and their colleagues thank the dietitians who supported the survey in each 
welfare facility for their valuable contribution. Financial support: This work was financially supported by a Health and Labour Sciences Research Grant (number H23Jyunkankitou(seishuu)-ippan-001) from the Ministry of Health, Labour and Welfare, Japan. The Ministry of Health, Labour and Welfare had no role in the design, analysis or writing of this article. Conflict of interest: None. Authorship: S.S. designed and directed the present study. S.M. managed field establishment and recruitment for the study. K.A. and K.U. collected and arranged the data. K.A. performed the statistical analyses and drafted the paper. All authors contributed to the development of the submitted manuscript. Ethics of buman subject participation: This study was conducted according to the guidelines laid down in the Declaration of Helsinki and all procedures involving human subjects were approved by the Ethics Committee of the University of Tokyo, Faculty of Medicine (approval number 10005, approval date 7 January 2013). Written informed consent was obtained from all participants.

\section{References}

1. He FJ, Li J \& Macgregor GA (2013) Effect of longer term modest salt reduction on blood pressure: Cochrane systematic review and meta-analysis of randomised trials. BMJ 346, f1325.

2. Aburto NJ, Ziolkovska A, Hooper L et al. (2013) Effect of lower sodium intake on health: systematic review and meta-analyses. BMJ 346, f1326.

3. Mozaffarian D, Fahimi S, Singh GM et al. (2014) Global sodium consumption and death from cardiovascular causes. $N$ Engl J Med 371, 624-634.

4. O'Donnell M, Mente A, Rangarajan S et al. (2014) Urinary sodium and potassium excretion, mortality, and cardiovascular events. $N$ Engl J Med 371, 612-623.

5. He FJ, Brinsden HC \& MacGregor GA (2014) Salt reduction in the United Kingdom: a successful experiment in public health. J Hum Hypertens 28, 345-352.

6. He FJ, Pombo-Rodrigues S \& Macgregor GA (2014) Salt reduction in England from 2003 to 2011: its relationship to blood pressure, stroke and ischaemic heart disease mortality. BMJ Open 4, e004549.

7. Laatikainen T, Pietinen P, Valsta L et al. (2006) Sodium in the Finnish diet: 20-year trends in urinary sodium excretion among the adult population. Eur J Clin Nutr 60, 965-970.

8. Department of Health (2011) Assessment of Dietary Sodium Levels among Adults (aged 19-64) in England, 2011. http:// transparency.dh.gov.uk/2012/06/21/sodium-levels-amongadults/ (accessed March 2015).

9. World Health Organization (2012) Guideline: Sodium Intake for Adults and Children. Geneva: WHO.

10. Ruzicka M, Hiremath S, Steiner S et al. (2014) What is the feasibility of implementing effective sodium reduction strategies to treat hypertension in primary care settings? A systematic review. J Hypertens 32, 1388-1394.

11. Asakura K, Uechi K, Sasaki Y et al. (2014) Estimation of sodium and potassium intakes assessed by two $24 \mathrm{~h}$ urine collections in healthy Japanese adults: a nationwide study. Br J Nutr 112, 1195-1205.

12. Shimbo S, Hatai I, Saito T et al. (1996) Shift in sodium chloride sources in past 10 years of salt reduction campaign in Japan. Tohoku J Exp Med 180, 249-259.
13. Miura K, Okuda N, Turin TC et al. (2010) Dietary salt intake and blood pressure in a representative Japanese population: baseline analyses of NIPPON DATA80. J Epidemiol 20, Suppl. 3, S524-S530.

14. Anderson CA, Appel LJ, Okuda N et al. (2010) Dietary sources of sodium in China, Japan, the United Kingdom, and the United States, women and men aged 40 to 59 years: the INTERMAP study. J Am Diet Assoc 110, 736-745.

15. Council for Science and Technology (editor) (2010) Standard Tables of Food Composition in Japan, fifth revised and enlarged edition 2010. Tokyo: National Printing Bureau.

16. Beer-Borst S, Costanza MC, Pechere-Bertschi A et al. (2009) Twelve-year trends and correlates of dietary salt intakes for the general adult population of Geneva, Switzerland. Eur J Clin Nutr 63, 155-164.

17. Andersen L, Rasmussen LB, Larsen EH et al. (2009) Intake of household salt in a Danish population. Eur J Clin Nutr 63, 598-604.

18. Fischer PW, Vigneault M, Huang R et al. (2009) Sodium food sources in the Canadian diet. Appl Physiol Nutr Metab 34, 884-892.

19. Tian HG, Hu G, Dong QN et al. (1996) Dietary sodium and potassium, socioeconomic status and blood pressure in a Chinese population. Appetite 26, 235-246.

20. Melse-Boonstra A, Rozendaal M, Rexwinkel H et al. (1998) Determination of discretionary salt intake in rural Guatemala and Benin to determine the iodine fortification of salt required to control iodine deficiency disorders: studies using lithium-labeled salt. Am J Clin Nutr 68, 636-641.

21. Wu SJ, Chang YH, Wei IL et al. (2005) Intake levels and major food sources of energy and nutrients in the Taiwanese elderly. Asia Pac J Clin Nutr 14, 211-220.

22. Sarno F, Claro RM, Levy RB et al. (2013) Estimated sodium intake for the Brazilian population, 2008-2009. Rev Saude Publica 47, 571-578.

23. Ainsworth BE, Haskell WL, Herrmann SD et al. (2011) 2011 Compendium of Physical Activities: a second update of codes and MET values. Med Sci Sports Exerc 43, 1575-1581.

24. Ministry of Health, Labour and Welfare (2009) Dietary Reference Intakes for Japanese, 2010. Tokyo: Daiichi Shippan Publishing Co., Ltd.

25. Kobayashi S, Murakami K, Sasaki S et al. (2012) Dietary total antioxidant capacity from different assays in relation to serum C-reactive protein among young Japanese women. Nutr J 11, 91.

26. Okubo H, Sasaki S, Murakami K et al. (2008) Three major dietary patterns are all independently related to the risk of obesity among 3760 Japanese women aged $18-20$ years. Int $J$ Obes (Lond) 32, 541-549.

27. Willett W (editor) (2013) Nutritional Epidemiology, 3rd ed. New York: Oxford University Press.

28. Mikkila V, Rasanen L, Raitakari OT et al. (2005) Consistent dietary patterns identified from childhood to adulthood: the Cardiovascular Risk in Young Finns Study. Br J Nutr 93, 923-931.

29. Statistic Bureau, Ministry of Internal Affaires and Communications (2011) Survey on Time Use and Leisure Activities. http://www.stat.go.jp/english/data/shakai/ (accessed March 2015).

30. Drewnowski A \& Popkin BM (1997) The nutrition transition: new trends in the global diet. Nutr Rev 55, 31-43.

31. Popkin BM (2006) Global nutrition dynamics: the world is shifting rapidly toward a diet linked with noncommunicable diseases. Am J Clin Nutr 84, 289-298.

32. Misra A \& Khurana L (2008) Obesity and the metabolic syndrome in developing countries. J Clin Endocrinol Metab 93, 11 Suppl. 1, S9-S30.

33. Otsuka R, Yatsuya H \& Tamakoshi K (2014) Descriptive epidemiological study of food intake among Japanese 
adults: analyses by age, time and birth cohort model. BMC Public Health 14, 328.

34. Matsumoto N (editor) (2012) Basic Data for Cooking, 4th ed. Tokyo: Kagawa Nutrition University Publishing Division.

35. Zhang J, Temme EH, Sasaki S et al. (2000) Under- and overreporting of energy intake using urinary cations as biomarkers: relation to body mass index. Am J Epidemiol 152, 453-462.

36. Murakami K, Sasaki S \& Uenishi K (2012) The degree of misreporting of the energy-adjusted intake of protein, potassium, and sodium does not differ among under-, acceptable, and over-reporters of energy intake. Nutr Res 32, 741-750. 